\title{
Submerged Macrophyte Restoration Differentiation for a Waterfront Body
}

\author{
Hua Wang, Fengqiang Ji, Jing Qin, and Yiyi Zhou
}

\begin{abstract}
The Inner Lake is a typical tide-influenced waterfront body in Eastern China. Series of environmental factors of the lake changed frequently and extensively due to its location. Regulating the water exchange for an improved living condition to restore macrophyte is very important to establish a healthy ecosystem. A differentiation function for submerged macrophyte restoration was proposed, and the numerical differentiation model was established, in which the projection pursuit theory was used to solve high-dimensional matters. The restoration areas of Vallisneria gigantean $\mathrm{L}$. in the Inner Lake in different hydrological years were forecasted. The results showed that the restoration regions in different typical years varied to some extent. The main restoration areas in the three years were similarly concentrated in the north and south parts in the lake. It was difficult to restore the macrophytes in the mainstream of the lake for its stronger water disturbance and higher suspended sediment concentration.
\end{abstract}

Index Terms-Differentiation, inner lake, restoration, submerged macrophyte, vallisneria gigantean $L$.

\section{INTRODUCTION}

Submerged macrophytes play an important part in aquatic ecosystems. They can provide food and shelters for aquatic animals, regulate nutrient dynamics within the system and prevent resuspension of the sediments [1]. However, on account of the increasing water pollution and accelerating water eutrophication, deterioration of submerged macrophytes has widely happened, which destroys the original ecological balance and eventually changed the macrophyte-dominated waterbody into the algae-dominated [2], [3]. To find a low-consumed and high-efficient technique to resolve these problems, submerged macrophyte restoration has been gradually focused on since the late 1970s, and presently it is widely used in water pollution control projects. Many experts have conducted series of researches in laboratory environment and explained some mechanisms about submerged macrophyte restoration to some extent [4]. However, there are few successful restoration cases in field practice. Submerged macrophytes always cannot survive diffusely and form steady communities. For example, Wang et al have failed twice to restore the macrophyte in Houhai in Beijing [5]; Li established the original submerged macrophyte communities under the controlled-isolated

Manuscript received May 10, 2013; revised June 28, 2013.This work was supported by the Major Science and Technology Program for Water Pollution Control and Treatment of China (No. 2012ZX07101-001).

H. Wang is with the Key Laboratory for Integrated Regulation and Resources Exploitation on Shallow Lakes, and Ministry of Education, Hohai University, Nanjing, China (e-mail: wanghua543543@163.com).

F. Q. Ji, J. Qin, and Y. Y. Zhou are with the Environmental College, Hohai University, Nanjing, China. environment in Wuli Lake, China, but they cannot live through the summers [6]. Lack of differentiation studies is an important reason for these frustrated cases. Many environmental factors, such as underwater light intensity, nutrient, temperature, deposited sediment, and water current, are included in the growth of submerged macrophytes, and the impacts of these factors always vary greatly. Differentiation study aims to quantificationally indicate the restoration feasibility of submerged macrophyte in a given field condition based on an integrated analysis of these influencing factors, and sequentially increase the restoration probability.

This current paper took the Inner Lake in Zhenjiang city, located in the middle-down reaches of the Yangtze River in Eastern China, as a research area. It is a typical tide-influenced waterfront body and due to its particular location and uncontrolled water exchange many environmental factors always change frequently and extensively. So we firstly introduced the habitat condition melioration schemes of the lake, which was very important for a favorable habitat, and then a differentiation function for macrophytes restoration was proposed. In view of the multi-dimensional factors included in the growth of macrophytes, a numerical differentiation model coupling water current, nutrient, suspended sediment, and underwater light intensity was proposed, and the projection pursuit principle was applied to solve the high dimensional problems in the model. Finally, the Vallisneria gigantean L. was selected as a typical restoration species, and the restoration areas of it in the Inner Lake in different hydrological years were forecasted based on the model.

\section{Materials AND MethodS}

\section{A. Description of the Study Area}

Zhenjiang, located at the convergence of the Yangtze River and the Jinghang Grand Canal, is a typical waterfront city in the Changjiang Delta in China. The Inner Lake, which is about $372 \mathrm{~km}$ away from the downriver estuary, is the main water body of Zhenjiang City. It is connected to the Yangtze River by the Leading Channel and joins the Yangtze River downstream at the Jiaonan Gate (Fig. 1), which results in a frequent water exchange between the lake and the Yangtze River.

The exchanged water volume per year is approximately between $4.5 \times 10^{9} \mathrm{~m}^{3}$ and $1.5 \times 10^{10} \mathrm{~m}^{3}$, and more than $85 \%$ of that is concentrated in the flood seasons [7]. Tides in the Yangtze River result in the high and low tides twice a day in the Inner Lake with the rising tide lasting $3.42 \mathrm{~h}$ and the ebb 
tide lasting $9.25 \mathrm{~h}$ on average. Due to the dual impacts of upstream runoff and external tides, the water level, water surface area, water volume, and dynamic conditions in the Inner Lake always change frequently in different typical years and tidal cycles (Table I), which induces series of environmental and ecological problems: a) During the flood seasons, plenteous water exchange can increase the environment carrying capacity of the lake and improve its water quality. However, due to the high suspended sediment concentration (SSC) of the coming water the overfull water may accordingly increase the SSC in the lake, that will aggrandize suspended sediment deposition and decrease the water transparency; b) In the dry seasons, SSC of the outer water body is reduced, but the low water level of the Yangtze River results in an insufficient water exchange, which will induce series of problems going against macrophyte restoration such as water quality deterioration, algae blooms, and increased bare bottomland; c) Frequent fluctuations of the habitat conditions always destroy the stability of the ecological system and add more difficulties to resume submerged macrophytes. Fig. 2 illustrates the annual processes of some factors of the lake in the common-water year of 2001. The reasons for these problems can be ascribed to the uncontrolled water exchange between the Inner Lake and the Yangtze River. Therefore, a pumping station was constructed on the Leading Channel (Fig. 1) to regulate the water exchanging process of the lake to stabilize its habitat conditions for macrophyte restoration.

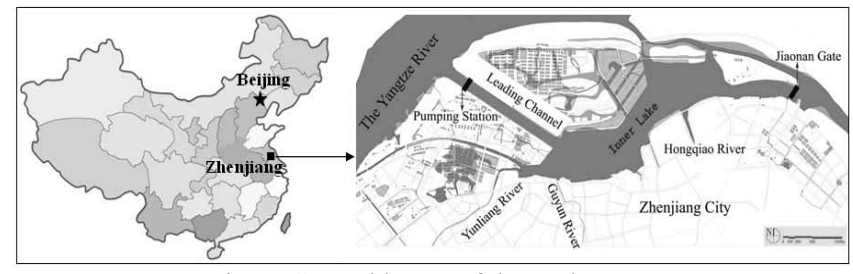

Fig. 1. General layout of the study area.

TABLE I: MORPHOLOGIC AND HYDROLOGIC CHARACTERS OF THE INNER

\begin{tabular}{lc}
\multicolumn{2}{c}{ LAKE } \\
\hline \hline \multicolumn{1}{c}{ Parameters } & Value range \\
\hline Water level (Yellow Sea basic plane, $\mathrm{m})$ & $1.0-6.7$ \\
Water surface area $\left(\mathrm{km}^{2}\right)$ & $2.8-6.8$ \\
Water volume $\left(10^{6} \mathrm{~m}^{3}\right)$ & $5.70-27.6$ \\
Daily spring tide duration $(\mathrm{h})$ & 3.42 \\
Daily ebb tide duration $(\mathrm{h})$ & 9.25 \\
Annual exchanging water volume between & $4.5-15.0$ \\
The Inner Lake and the Yangtze River $\left(10^{9} \mathrm{~m}^{3}\right)$ & \\
\hline \hline
\end{tabular}

\section{B. Habitat Conditions Melioration}

The most important way to meliorate the habitat conditions for the Inner Lake is to regulate the uncontrolled water exchange. In view of the hydrological conditions of the Yangtze River and the lake, the water exchanging progress was regulated by the following principles: a) During the flood seasons, considering the higher SSC of the Yangtze River, water exchange should be controlled to depress sediment deposition and increase water transparency. The inflowing water with high SSC should be obviated and that with low SSC should be introduced as much as possible. b) In the dry seasons, the outer low water level results in an insufficient water exchange, so the pumping station at the Leading Channel should be used to reinforce water exchange to improve water carrying capacity and keep the ecological water demand. c) The water regulation scheme should consider the detailed water demands in different growth periods of submerged macrophytes and the water level of the lake should be controlled to meet the requirements for macrophyte restoration. d) After regulation the modes of water exchange of the lake include three types. The first one is "Self-introducing". This mode is always used when the water level of the Yangtze River is high enough, and in this situation water exchanges in a natural way. The second type is "Pumping". This mode is usually selected when the outer water level is too low to precede natural water exchange, and the pumping station will be used in this mode. The last one is "Keeping static condition". This mode is always needed after water exchange for the sedimentation of suspended sediments and the increase of water transparency. Specific schemes have been documented in [8]. By regulation, the natural exchanged water volume was balanced, the SSC of the lake was decreased and the water transparency was increased.

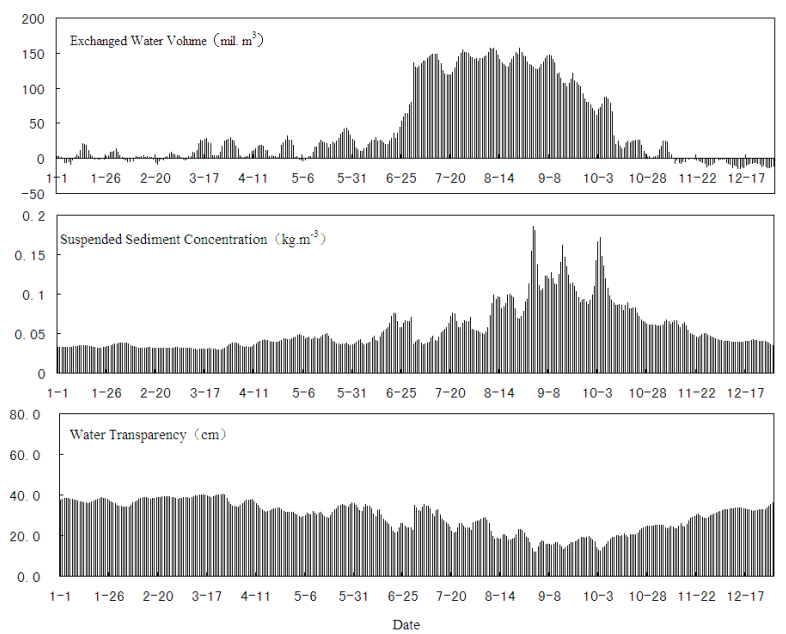

Fig. 2. Present environmental processes of the Inner Lake in a common-water year.

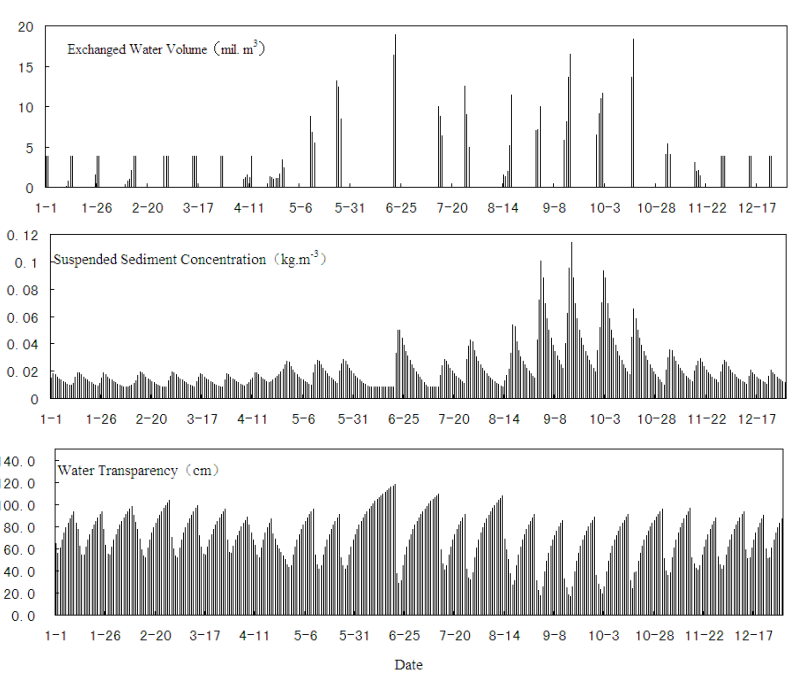

Fig. 3. Environmental processes of the Inner Lake after water regulation in a common-water year.

Habitat condition of the Inner Lake was obviously 
improved for macrophyte restoration. The corresponding processes in Fig. 2 after water regulation were shown in Fig. 3.

\section{Numerical Differentiation Model}

\section{1) Differentiation function}

Many present researches have indicated that the growth of submerged macrophytes is influenced by multi-environmental factors such as underwater light intensity, nutrient concentration, suspended sediment, water current, temperature, and deposited sediment [9] (Fig. 4). However, different water bodies always face different environmental problems, and the dominating influencing factors considered in macrophyte restoration vary widely. So in a given habitat condition, a differentiation criterion considering these influencing factors is very important to estimate whether the macrophytes can be restored or not. In view of the field environmental characters of the Inner Lake, the criterion for submerged macrophyte restoration was put forward based on both the Least Factor Law of Justus-Liebig and the Tolerance Law of Shelford, which can be expressed as follows: 1) Water current, nutrient, suspended sediment, and underwater light intensity are the main influencing factors considered in macrophyte restoration for the Inner Lake; 2) Pure underwater light intensity is the fateful factor for the growth of macrophytes. In field conditions, it should meet the light compensation point of macrophytes, or else they cannot be restored; 3) The other three factors can be boiled down to tolerant factors, and the general impacts of these factors on macrophytes should range in the tolerance limits. If the external action on macrophytes exceeds the limits, they cannot be restored (Fig. 5). The criterions can be translated to the functions as in (1):

$$
M=F(I) \cdot G\left(K_{1}, K_{2}, K_{3}\right)
$$

where $M$ is the differentiation function for macrophyte restoration; $I$ is the pure underwater light intensity; $K_{1}, K_{2}, K_{3}$ represent nutrient concentration, suspended sediment, and water current, respectively. $F$ is the growth limiting function related to underwater light intensity; $G$ is the general influencing function with other three factors being considered.

$$
F(I)=\left\{\begin{array}{l}
1, I \geq I_{0} \\
0, I<I_{0}
\end{array}\right.
$$

where $I_{0}$ is the light compensation point of macrophytes, which can keep well-balanced photosynthesis.

$$
\begin{aligned}
& G\left(K_{1}, K_{2}, K_{3}\right)= \\
& \left\{\begin{array}{l}
1, P_{\text {min }} \leq P\left(K_{1}, K_{2}, K_{3}\right) \leq P_{\text {max }} \\
0, P\left(K_{1}, K_{2}, K_{3}\right)>P_{\text {max }} \text { 或 } P\left(K_{1}, K_{2}, K_{3}\right)<P_{\text {min }}
\end{array}\right.
\end{aligned}
$$

where $P\left(K_{1}, K_{2}, K_{3}\right)$ is the integrated impacts of the factors on macrophyte growth; $P_{\min }$ and $P_{\max }$ are respectively the minimum and the maximum tolerant limit value; The gap between $P_{\min }$ and $P_{\max }$ is the tolerant extent of the environmental factors to macrophyte growth.

Based on formula (2) and (3), the results of function $M$ can be calculated. If $M$ equals to 1 , the submerged macrophytes can be resumed, or else it can not.
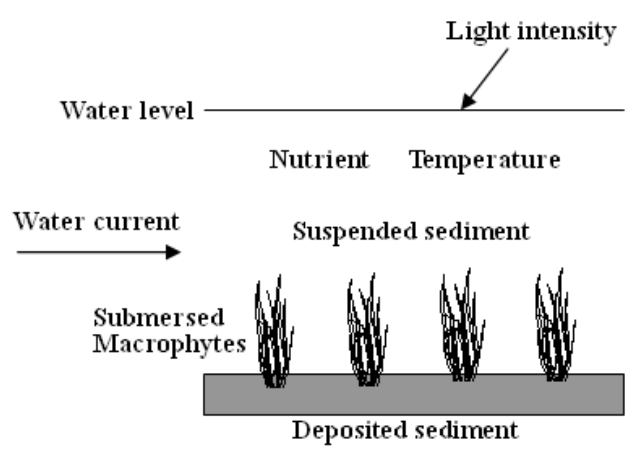

Fig. 4. Factors involved in the growth of submerged macrophytes.

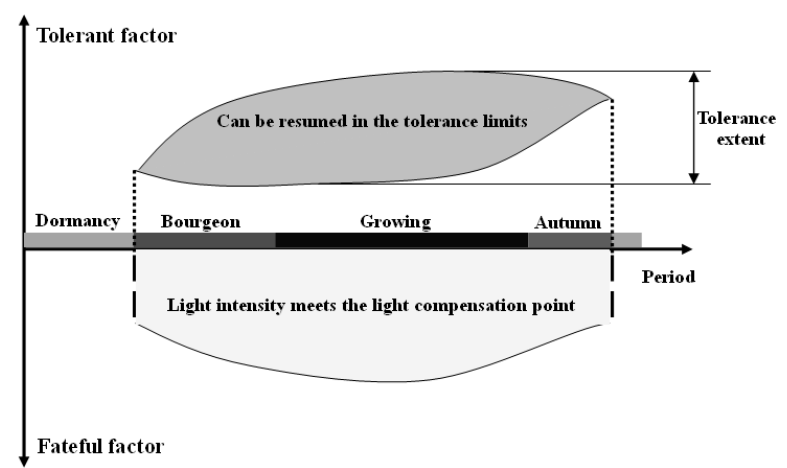

Fig. 5. Criterions for submerged macrophyte restoration in the Inner Lake.

\section{2) Numerical model structure}

The function proposed above established the essential foundation for differentiating the restoration area of macrophytes. However, to get an in-depth and quantificational investigation, it is very important to learn the changing mechanisms of the influencing factors considered in the function by numerical simulations. Therefore we put forward a numerical model, which was composed of three parts. The first part is the multi-factor coupled simulation module, which aims to simulate the temporal and spatial processes of the environmental factors in a field habitat. The second part is the data analysis and processing module. Because many factors were considered in the function, to solve the differentiation function is to solve a high-dimension numerical problem. How to reflect the integrated impacts of all the factors on macrophyte growth, and how to change the multi-dimension problem to a single one are of great importance. This module used projection pursuit theories to tackle these problems. The last part of the model is the result output module (Fig. 6).

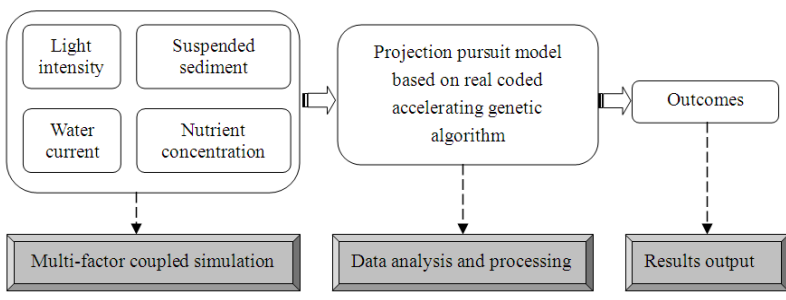

Fig. 6. Numerical differentiation model for submerged macrophyte restoration in the Inner Lake.

\section{3) Radical controlling equations}

a) Two-dimension unsteady flow equation

The conservation forms of two-dimensional shallow water 
equations are written as in (4):

$$
\left\{\begin{array}{l}
\frac{\partial h}{\partial t}+\frac{\partial(h u)}{\partial x}+\frac{\partial(h v)}{\partial y}=0 \\
\frac{\partial(h u)}{\partial t}+\frac{\partial\left(h u^{2}+g h^{2} / 2\right)}{\partial x}+\frac{\partial(h u v)}{\partial y}=g h\left(s_{0 x}-s_{f x}\right) \\
\frac{\partial(h v)}{\partial t}+\frac{\partial(h u v)}{\partial x}+\frac{\partial\left(h v^{2}+g h^{2} / 2\right)}{\partial y}=g h\left(s_{0 y}-s_{f y}\right)
\end{array}\right.
$$

where $h$ is water depth; $t$ is time; $u$ and $v$ are depth-averaged velocity components in the $x$ and $y$ directions, respectively; $g$ is the acceleration of gravity; $s_{0 x}$ and $s_{f x}$ are the bed slope and friction slope in the $x$ direction, and $s_{0 y}$ and $s_{f y}$ are the bed slope and friction slope in the $y$ direction.

b) Two-dimension convection-diffusion equation

The pollutant convection-diffusion equation can be written as in (5):

$$
\begin{gathered}
\frac{\partial\left(h C_{i}\right)}{\partial t}+\frac{\partial\left(h u C_{i}\right)}{\partial x}+\frac{\partial\left(h \nu C_{i}\right)}{\partial y}= \\
\frac{\partial}{\partial x}\left(D_{x}^{i} h \frac{\partial C_{i}}{\partial x}\right)+\frac{\partial}{\partial y}\left(D_{y}^{i} h \frac{\partial C_{i}}{\partial y}\right)-K_{i} h C_{i}+W_{i}
\end{gathered}
$$

where $C_{i}$ is the depth-averaged pollutant concentration; $D_{x}^{i}$ and $D_{v}^{i}$ are the dispersion coefficient of pollutants in the $x$ and $y$ directions under dynamic condition, respectively; $K_{i}$ is the degradation coefficient; $W_{i}$ is the source-sink vector of pollutants, which is closely related to field dynamic conditions.

\section{c) Suspended sediment transportation equation}

Considering the diffusion and resuspension of suspended sediment under water current disturbance, the two-dimensional suspended sediment transportation equation is written as in (6):

$$
\begin{aligned}
& \frac{\partial(h S)}{\partial t}+\frac{\partial(h u S)}{\partial x}+\frac{\partial(h v S)}{\partial y}= \\
& \frac{\partial}{\partial x}\left(E_{x} h \frac{\partial S}{\partial x}\right)+\frac{\partial}{\partial y}\left(E_{y} h \frac{\partial S}{\partial y}\right)+F_{s}
\end{aligned}
$$

where $S$ is the suspended sediment concentration; $E_{x}$ and $E_{y}$ are the dispersion coefficient of suspended sediments in the $x$ and $y$ directions under dynamic condition; $F_{s}$ is the source-sink vector of suspended sediments and it can be expressed as in (7):

$$
\begin{gathered}
F_{s}=-A \alpha \omega_{s} S\left(1-\frac{u^{2}}{u_{d}^{2}}\right)+B M\left(\frac{u^{2}}{u_{e}^{2}}-1\right), \\
A=\left\{\begin{array}{l}
1, u \leq u_{d} \\
0, u>u_{d}
\end{array}, B=\left\{\begin{array}{l}
1, u \geq u_{e} \\
0, u<u_{e}
\end{array}\right.\right.
\end{gathered}
$$

where $\alpha$ is the sedimentation probability; $\omega_{s}$ is the sedimentation velocity; $u_{d}$ is the non-depositing critical velocity; $u_{e}$ is the incipient critical velocity; when $u \leq u_{d}$, the suspended sediment will be deposited, or else, it will be resuspended.

\section{d) Underwater light intensity distribution model}

The attenuation of light intensity in water body is induced by both absorption and dispersion. Different water bodies have different physical components, and the light attenuation varies greatly. The solar radiations of different wavelengths have various attenuation mechanisms in different water layers. A simplified mode was used in the paper to reflect the underwater attenuation process of light intensity, which can be written as in (8):

$$
I_{h}=I_{0} e^{-k h}
$$

where $I_{0}$ is the primary light intensity at the water surface; $h$ is the water depth; $I_{h}$ is the light intensity at the depth of $h ; k$ is the optics attenuation coefficient, which is closely related to the suspended sediment concentration, nutrient concentration and so on.

The water flow, water quality, temperature, and suspended sediment controlling equations can be combined to be calculated. Formulas (4), (5) and (6) can be written as the unified form in (9):

$$
\frac{\partial q}{\partial t}+\frac{\partial f(q)}{\partial x}+\frac{\partial g(q)}{\partial y}=b(q)
$$

where $q$ is the vector of the conserved physical quantities; $f(q)$ and $g(q)$ are respectively the flux vectors in the $x$ and $y$ directions; $b(q)$ is the source-sink vector; the detailed expressions are as in (10):

$$
\left\{\begin{aligned}
q & =\left(h, h u, h v, h C_{i}, h \Delta T, h S\right)^{\mathrm{T}} \\
f(q) & =\left(h u, h u^{2}+g h^{2} / 2, h u v, h u C_{i}, h u \Delta T, h u S\right)^{\mathrm{T}} \\
g(q) & =\left(h v, h u v, h v^{2}+g h^{2} / 2, h v C_{i}, h v \Delta T, h v S\right)^{\mathrm{T}} \\
b(q) & =\left(0, g h\left(S_{0 x}-S_{f x}\right), g h\left(S_{0 y}-S_{f y}\right), \nabla \cdot\left(D_{i} \nabla\left(h C_{i}\right)\right)-K_{i} h C_{i}+W,\right. \\
& \left.\nabla \cdot\left(D^{\prime} \nabla(h \Delta T)\right)-\left(K_{s} \cdot \Delta T\right) / \rho C_{p}, \nabla \cdot\left(E_{i} \nabla(h S)\right)+F_{s}\right)^{\mathrm{T}}
\end{aligned}\right.
$$

In which superscript $T$ is the transposing operator; $\nabla$ is the gradient operator.

Developed in the framework of finite volume method (FVM) on an unstructured grid, the flux vector splitting (FVS) scheme was employed to calculate the numerical normal flux of variables across the interface between grids. The underwater light intensity can be calculated by formula (8) solely.

\section{4) Data processing with projection pursuit}

Based on the simulation results of different environmental factors, the functions of $F$ and $G$ should be solved to forecast the restoration area of submerged macrophytes. The function $F$ can be directly calculated by the numerical model, but how to deal with the function $G$ is a key problem. Generally, a separate influencing factor is a separate parameter, and the system under multi-impact of $n$ factors can be regarded to be a $n$-dimensional problem. Here three tolerant factors including water current, nutrient, suspended sediment are considered, so to deal with the function $G$ is to tackle a 3-dimension problem. In this paper, the projection pursuit theory was selected to turn the high-dimensional matter into a one-dimension index, which was popularly used in the recent 20 years. The basic steps are as follows: a) Project the high dimensional data to low dimensional space by certain combination; b) Use the projection index function to reflect the possibility of exposing some configurations, and find out the best projection value to optimize the projection index 
function; c) Analyze the structural characters of the high dimensional data according to the projection value. Conformation and optimization of the projection index function is the key problem in projection pursuit.

\section{RESULTS AND DISCUSSION}

\section{A. Calculation Conditions}

Water regulation between the Inner Lake and the Yangtze River made an improved habitat for submerged macrophyte restoration, and the established numerical differentiation model made it possible to conduct a farther quantitative study. In view of the different living conditions in the Inner Lake in different years, three typical water years, the high-water year (1998), the common-water year (2000), and the low-water year (2004) were selected as the representative studied phases. The macrophyte of Vallisneria gigantean L. was selected as the pioneer species for its extensive adaptability, which used to be a leading species in the Inner Lake. Considering the different growing periods of Vallisneria gigantean L., the spring (bourgeoning period) and the summer (growing period) were selected as the calculated periods of time in each typical year. The water area, of which the values of the differentiation function $M$ in different calculated periods are all equal to 1 , is considered to be possible for submerged macrophyte restoration.

Calculated region was the Inner Lake. According to the terrain characters it was divided into 2642 quadrilateral grids and 2880 nodes. The mean grid size was $50 \mathrm{~m} \times 50 \mathrm{~m}$. There are five open boundaries, the upper section of the leading channel, the Yunliang River, the Hongqiao Harbor, the Guyun River, and the Jiaonan Gate in the model, with the first three sections being inflowing boundaries and the last two out flowing. The water levels, water flow rates and pollutant concentrations at the open boundaries were obtained from the field measured data. The time steps in the model of water current and pollutant transport were $0.1 \mathrm{~s}$ and $1 \mathrm{~s}$ respectively. Considering the spatial discrepancy, the roughness coefficients were taken between 0.02 and 0.05 . The turbulent viscosity coefficient was $0.2 \mathrm{~m}^{2} \cdot \mathrm{s}^{-1}$, and the wind drag coefficient was $1.0 \times 10^{-3}$. The eigenvalues of the factors considered in the growth of Vallisneria gigantean L. were obtained by laboratory experiments and documented results [10]-[15], which were shown in Table II.

TABLE II: EIGENVALUES OF THE FACTORS CONSIDERED IN THE GROWTH OF VALLISNERIA GIGANTEAN L.

\begin{tabular}{cccc}
\hline \hline $\begin{array}{c}\text { Restricting } \\
\text { factor }\end{array}$ & \multicolumn{3}{c}{ Tolerant factors } \\
\hline $\begin{array}{c}\text { Light } \\
\text { intensity } \\
\left(\mu \mathrm{mol} \cdot \mathrm{m}^{-2} \cdot \mathrm{s}^{-1}\right)\end{array}$ & $\begin{array}{c}\text { Nutrients(TN) } \\
\left(\mathrm{mg} \cdot \mathrm{L}^{-1}\right)\end{array}$ & $\begin{array}{c}\text { Suspended sediment } \\
(\mathrm{NTU})\end{array}$ & $\begin{array}{c}\text { Water } \\
\text { current } \\
\left(\mathrm{m} \cdot \mathrm{s}^{-1}\right)\end{array}$ \\
$\geq 9.4$ & $0.5-8$ & $0-30$ & $0.01-0.09$ \\
\hline \hline
\end{tabular}

\section{B. Restoration Area Forecast}

Based on projection pursuit, the software MATLAB6.0 was used to deal with the results of numerical simulations. According to a given calculated grid, the father-generation initial population scale $n=400$, crossover probability $P_{c}=400$, mutation probability $P_{m}=0.8$, and the excellent individual amount is 20 . Based on the established numerical model, the water area, where the macrophyte Vallisneria gigantean L. can be restored, was forecasted for different level years (Fig. 7).

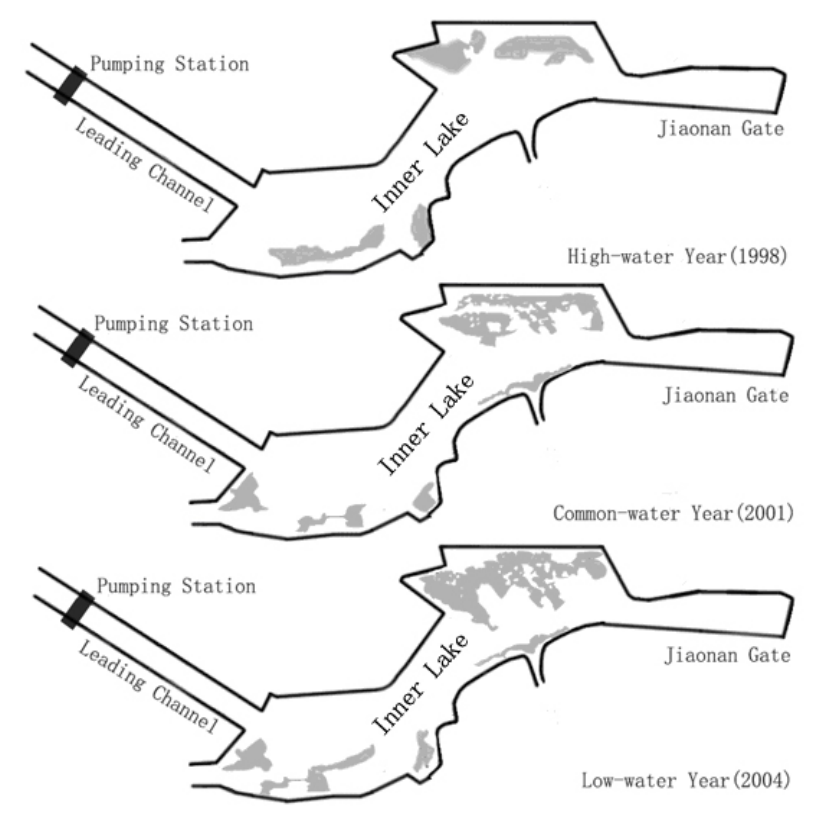

Fig. 7. Restoration areas of Vallisneria gigantean L. in the Inner Lake in different level years.

It was found that, due to the disparities in the hydrological conditions and the sediment concentrations, the areas of the macrophyte restoration region in different typical years vary to some extent. The total restoration areas in the high-water year, common-water year, and low-water year were respectively $0.67 \mathrm{~km}^{2}, 1.06 \mathrm{~km}^{2}$, and $1.01 \mathrm{~km}^{2}$. Averagely, the restoration region approximately accounts for $13.4 \%$ of the total water surface. The main restoration areas were concentrated in the north and south parts of the lake, and it was difficult to restore the macrophytes in the mainstream area because of the stronger water disturbance and the higher suspended sediment concentration.

\section{CONCLUSIONS}

Due to the complex impacts of series of factors involved in the growth of submerged macrophytes, it is still a difficult problem to quantificationally forecast the restoration areas of them in a given field habitat. In this paper, a typical waterfront body, the Inner Lake, located in the middle-down reaches of the Yangtze River in Eastern China was selected as the research area to make a primal investigation on this topic. In a natural condition, many environmental factors of the Inner Lake always changed frequently and extensively, which leaded to a poor habitat for submerged macrophyte restoration. However, by water quantity regulation the living conditions of the Lake can be improved obviously to restore macrophytes. A numerical function was originally proposed to differentiate the restoration area for macrophytes, which included four influencing factors, underwater light intensity, water current, nutrient, and suspended sediment. Based on the function the numerical differentiation model for submerged macrophyte restoration was established, and the 
projection pursuit theory was used to solve the multi-dimensional problems. Eventually, the macrophyte of Vallisneria gigantean L. was selected as the pioneer species and the restoration areas in the Inner Lake in different typical years were forecasted. The results showed that the restoration regions in different years were similarly concentrated in the north and south part of the Inner Lake, and the area was averagely $13.4 \%$ of the whole water surface.

Submerged macrophytes always play an important part in the biologic and chemic cycles in water bodies, and occupy the key interface in the aquatic ecosystems. During the recent decades, restoration and reconstruction of submerged macrophytes is gradually attended by more and more experts. The results of this paper will to some extent promote quantitative investigations on field submerged macrophyte restoration, and will make an important contribution to establish a steady and healthy aquatic ecosystem for the studied area.

\section{REFERENCES}

[1] V. D. Elln, J. Wouter, and B. Vande, "Impact of submerged macrophyte including charophytes on phyto-and zooplankton communities: allelopathy versus other mechanisms," Aquatic Botany, vol. 72, pp. 267-274, 2002

[2] J. K. Sand and T. Riis, "Vestergaard O, macrophyte decline in Danish lakes and streams over the past 100 years," Journal of Ecology, vol. 88 , pp. $1030-1040,2000$

[3] S. Korner, "Loss of submerged macrophytes in shallow lakes in north-eastern Germany," International Review of Hydrobiology, vol. 87, pp. $75-384,2002$

[4] N. Takamura, Y. Kadono, and M. Fukushima, "Effects of aquatic macrophytes on water quality and phytoplankton communities in shallow lakes," Ecological Research, vol. 18, pp. 381-395, 2003.

[5] S. H. Wang, D. F. Zhao, and R. H. Liao, "Research on water body illuminance and compensation depth of submerged macrophyte in lake," Technology of Water Treatment, vol. 32, pp. 31-33, 2006.

[6] W. C. Li, "Ecological restoration of shallow, eutrophic lakes experimental studies on the recovery of aquatic vegetation in Wuli Lake," Journal of Lake Science, vol. 8, pp. 1-9, 1996.

[7] H. Wang, Y. Pang, L. Ding, M. Y. Liu, and H. H. Zhuang, "Numerical simulation of transparency for waterfront body and application research," Tsinghua Science and Technology, vol. 13, pp. 720-729, 2008.

[8] H. Wang, Y. Pang, and S. B. Liu, "Research progress on influencing of environmental factors on the growth of submersed macrophytes," Acta Ecologica Sinica, vol. 28, pp. 3958-3968, 2008.

[9] K. Michael and B. Richard, "Habitat requirements for submerged aquatic vegetation in chesapeake bay: water quality, light regime, and physical-chemical factors," Estuaries, vol. 27, pp. 363-377, 2004.

[10] J. H. Friedman and J. W. Tukey, "A projection pursuit algorithm for exploratory data analysis," IEEE Trans. on Computer, vol. 23, pp. 881-890, 1974

[11] E. P. H. Best, "Effects of nitrogen on the growth and nitrogenous compounds of ceratophyllum demersum," Aquatic Botany, vol. 8, pp. 197-206, 1980.

[12] C. Ye, G. Y. Zhou, Z. S. Fu, X. F. Song, H. C. Yu, and H. N. Kong, "Responses of three submerged macrophytes to total nitrogen supply," Acta Scientiae Circumstantiae, vol. 27, pp. 739-745, 2007.

[13] W. L. Wang, G. X. Wang, and Q. Li, "Influence of suspended substance o growth of the seedlings of Vallisneria asiatica miki L," Acta Hydrobiologica Sinica, vol. 31, pp. 460-465, 2007.

[14] J. D. Madsen, P. A. Chambers, and W. F. James, "The interaction between water movement, sediment dynamics and Submerged macrophytes," Hydrobiologia, vol. 444, pp. 71-84, 2001.

[15] Y. F. Xie, C. H. Li, Z. W. Liu, G. R. Chen, and Z. X. Lei, "Effects of Sediments on the Growth and Morphology of Vallisneria natans," Journal of Agro-Environment Science, vol. 26, pp. 1269-1272, 2007.

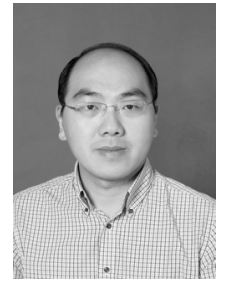

Hua Wang was born in Taizhou, Jiangsu Province, China in 1983, He is a doctor of Engineering and laureate of Baosteel Educational Award. He graduated and obtained bachelor degree of engineering from Hohai University, Nanjing, Jiangsu Province, China in 2004. He graduated and obtained doctorate degree of engineering from Hohai University, Nanjing, Jiangsu Province, China in 2009. His major field of study is the water environment protection and numerical

\section{simulation.}

He has been a lecturer of department of environmental engineering of Hohai University, Nanjing, Jiangsu Province, China since Sep. 2009. Since then, he has participated in the 863 projects of China, the Eleventh Five-year Plan and Twelfth Five-year Plan for the Major Science and Technology Program for Water Pollution Control and Treatment of China. He has published more than 20 papers in domestic and abroad core journals. There are 2 papers that can be searched in SCI and 9 can be searched in EI and ISTP, e.g. "water quality operation to achieve multi-environmental goals for a waterfront body," water resources management, vol. 23, pp. 1591-1968, 2009; "investigation of internal pollutant loading for a tide-influence waterfront body," water environment research, vol. 81, pp. 2437-2446, 2009; "numerical simulation of transparency for waterfront body and application research," tsinghua science and technology, vol. 13, pp. 720-729, 2008 .

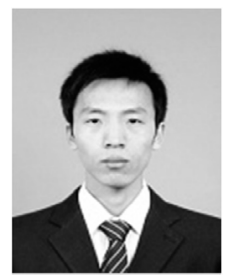

Fengqiang Ji was born in Dezhou, Shandong Province, China in 1989, He is a Bechelor of Science. He graduated and obtained bachelor degree of science from Shandong Agriculture University, Taian, Shandong Province, China in 2011. His major field of study is the water environment protection and numerical simulation.

He was an undergraduate of environmental science of Shandong Agriculture University, Taian, Shandong Province, China from Sep. 2007 to July 2011, and has been a graduate student of environmental science and engineering of Hohai University, Nanjing, Jiangsu Province, China since Sep. 2011. He has participated in the Twelfth Five-year Plan for the Major Science and Technology Program for Water Pollution Control and Treatment of China. He has published about 3 papers in domestic core journals,e.g. "Study on spatio-temporal distribution of water transparency for Zhen-Yang Section of the Yangtze River," Journal of Hydroelectric Engineering, 2013.

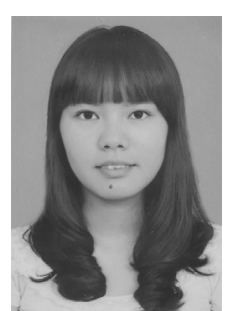

Qin Jing was born in Nanning, Guangxi Province, China in 1988. She is a master of engineering. She graduated and obtained bachelor degree of engineering from Guangxi Normal University, Guilin, Guangxi Province, China in 2011. She graduated and obtained master degree of engineering from Hohai University, Nanjing, Jiangsu Province, China in 2013. Her field of study is the water environment protection and numerical simulation.

She was an undergraduate of environmental science of Guangxi Normal University, Guilin, Guangxi Province, China from Sep. 2007 to July 2011, and she has been a graduate student of environmental science and engineering of Hohai University, Nanjing, Jiangsu Province, China since Sep. 2011. She has published 3 papers in domestic core journals, e.g. "Study on spatio-temporal distribution of water transparency for Zhen-Yang Section of the Yangtze River," Journal of Hydroelectric Engineering, 2013.

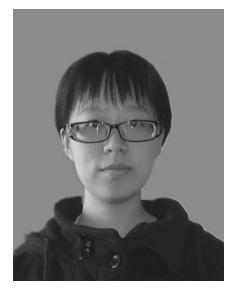

Yiyi Zhou was born in Yixing, Jiangsu Province, China in 1991. She has been studying in Environmental College, Hohai University, Nanjing, Jiangsu Province, China since Sep. 2009. Her major field of study is the water environment protection and numerical simulation.

She is to graduate and obtain bachelor degree of science from Hohai University in June. 2013, and to be a graduate student of Hohai University in Sep. 2013 for further study. She has had one paper to be published, "Investigation on Eutrophication Level for Gucheng Lake by the Model of Butterfly Catastrophe," Advanced Materials Research, 2013. 